\title{
Author Index Volume 26 (2006)
}

The issue number is given in front of the page numbers.

Attanasio, P., The impact of technology on European small and medium-sized publishers

(2) $109-113$

Ball, R. and D. Tunger, Science indicators revisited - Science Citation Index versus SCOPUS: A bibliometric comparison of both citation databases

(4) $293-301$

Bessis, N. and C. Oppenheim, Making the DREAM reality: A SSM based model for the communication of design research

Bolman, P., The significance of April 4th, a reflection

Bošnjak, A., see Seljak, T.

Cockerill, M., The economics of open access publishing

Cockerill, M., see Tracz, V.

Cravedi, K., see Siegel, E.R.

de Kemp, A., E. Fredriksson and B. Ortelbach, Preface

Decker, S., The social semantic desktop: Next generation collaboration infrastructure

Demaine, J., see Dumouchel, B.

Dewandre, N., Scientific publications: A key factor of the European research area

Dumouchel, B. and J. Demaine, Knowledge Discovery in the Digital Library: access tools for mining science

(3) $223-240$

(2) $117-120$

(4) 303-308

(2) $151-157$

(2) $103-107$

(1) $1-10$

(2) $57-58$

(2) $139-144$

(1) $39-44$

(2) $65-72$

(1) 39- 44

Fournier, J., see Gersmann, G.

Fredriksson, E., see de Kemp, A.

Fredriksson, E.H., Dr. Ekkehard Hundt

(2) $147-150$

(2) $57-58$

(2) 207-208

Gersmann, G. and J. Fournier, Providing and accessing scientific literature. How the German Research Foundation (DFG) supports scholarly communication

Geurts, P.A.Th.M., see Kurek, K.

(2) $147-150$

(4) $271-282$

Haank, D., Academic publishing is electronic publishing

(2) $81-83$

Hajarian, K., see Siegel, E.R.

Harnsberger, R.L., see Siegel, E.R.

Hauer, M., Retrieval quality of library catalogues and new concepts. A comparison

Helander, P., Aspects of using and producing information resources: EUSIDIC Annual Conference 2006

Helliwell, J.R., P.R. Strickland and B. McMahon, The role of quality in providing seamless access to information and data in e-science; the experience gained in crystallography

(1) $1-10$

(1) $1-10$

(3) $241-248$

(4) $309-312$

(1) $45-55$ 
Honnefelder, G., The role of information in science and society

(2) $61-63$

Hoole, D., The changing geography of an industry and a debate

(2) $87-95$

Jansen, H., Permanent access to electronic journals

(2) $129-134$

Kol, N.J.C., R.J. van Diessen and K. van der Meer, An improved Universal Virtual Computer approach for long-term preservation of digital objects

Krause, J.A., see Siegel, E.R.

Kurek, K., P.A.Th.M. Geurts and H.E. Roosendaal, The split between availability and selection

(4) $283-291$

(1) $1-10$

(4) $271-282$

Lewandowski, D., Query types and search topics of German Web search engine users

(4) $261-269$

Lindberg, D.A.B., see Siegel, E.R.

Logan, R.A., see Siegel, E.R.

Lyon, B., see Siegel, E.R.

(1) $1-10$

(1) $1-10$

(1) $1-10$

Marlow, M., E-volution of Revolution: Some observations on emerging trends in content, technology and service provision

McMahon, B., see Helliwell, J.R.

Moed, H.F., New developments in citation analysis and research evaluation

Molholm, K.N., Standards and interoperability

Natarajan, M., Use of online technology for multimedia education

Nielsen, H.P., Science authorship - product support - information consumer

Olivieri, R., New masters, new rules

Oppenheim, C., see Bessis, N.

Ortelbach, B., see de Kemp, A.

Renn, J., Towards a web of culture and science

Roosendaal, H.E., see Kurek, K.

Ruffin, A., see Siegel, E.R.

Seeley, M., Impact of the Internet on the services aspect of the STM publishing business

Seljak, T. and A. Bošnjak, Researchers' bibliographies in COBISS.SI

Siegel, E.R., Editor's introduction

Siegel, E.R., R.A. Logan, R.L. Harnsberger, K. Cravedi, J.A. Krause, B. Lyon, K. Hajarian, J. Uhl, A. Ruffin and D.A.B. Lindberg, Information Rx: Evaluation of a new informatics tool for physicians, patients, and libraries

Sörensen, A., From copyright to access rights? How public policy might shape industry strategies

Sprang, C., Strategic change - in which direction?

Spruijt, H.P., Closing panel

Stalmans, W., Publishing constraints experienced by a large European scientific society

Strickland, P.R., see Helliwell, J.R.

Tenopir, C., Building bridges to information products and services

Tracz, V. and M. Cockerill, What shall we do? Challenges and opportunities of the coming changes in science publishing

(2) $191-197$

(1) $45-55$

(2) $135-137$

(1) 29- 37

(3) 249-256

(2) 165-169

(2) $159-163$

(3) $223-240$

(2) $57-58$

(2) $73-79$

(4) $271-282$

(1) $1-10$

(2) $173-175$

(4) 303-308

(1) $11-12$

(1) $1-10$

(2) 185-189

(2) $177-183$

(2) 201-204

(2) 97-101

(1) $45-55$

(3) $213-221$

(2) 103-107

Tunger, D., see Ball, R.

(4) 293-301 
Uhl, J., see Siegel, E.R.

(1) $1-10$

van der Meer, K., see Kol, N.J.C.

(4) $283-291$

van Diessen, R.J., see Kol, N.J.C.

(4) 283-291

White, M., The search for Eureka

(2) $123-127$ 